\section{AB0708 HIGH DRUG RETENTION RATES DESPITE B/ TSDMARD INTERRUPTIONS IN COVID-19 PANDEMIC CHAOS}

S. Gulle ${ }^{1}$, Y. Erez ${ }^{1}$, A. Karakas ${ }^{1}$, T. Yüce İnel ${ }^{1}$, S. B. Kocaer ${ }^{2}$, T. Demirci Yıldırım ${ }^{1}$, G. Can ${ }^{1}$, I. Sari', M. Birlik', F. Onen ${ }^{1} .{ }^{1}$ Dokuz Eylul University Faculty of Medicine, Rheumatology, Izmir, Turkey; ${ }^{2}$ Kastamonu Research and Training Hospital, Rheumatology, Kastamonu, Turkey

Background: A significant increased risk of COVID-19 related adverse outcomes of the biological or target-directed synthetic DMARDs (b/tsDMARDs) has not yet been reported. For this reason, it is recommended to continue b/ tsDMARD treatments with maximum compliance with pandemic measures. Objectives: The aim of this study was to evaluate the effects of patients using b/tsDMARDs on drug survival and rheumatic disease control during pandemic. Methods: In this study, patients diagnosed with rheumatic disease using b/tsDMARDs and who were followed up during the 12-month period (January 20202021) including the onset of the Covid-19 pandemic at Dokuz Eylul University Faculty of Medicine Rheumatology Clinic were evaluated. In the first 3 months of the pandemic (March-June 2020), the patients skipped at least 2 cycles of treatment with the fear of Covid-19 infection except for infection / surgical reasons was considered as a disruption of the drug. The drug retention rates of the patients on $\mathrm{b} / \mathrm{tsDMARDs}$ treatments during the pandemic process and the factors affecting this situation were evaluated.

Results: The rate of disrupting their b/tsDMARDs was higher in patients> 65 years of age, with a diagnosis of RA and who needed to come to the hospital for bDMARD treatment $(p=0.007, p=0.015$ and $p=0.004$, respectively).

The overall 1-year b/tsDMARD retention rates was found $91 \%$. It was determined that a history of interruption in b/tsDMARD treatments in the first 3 months of the pandemic [OR: $1.28(\mathrm{Cl}: 1.042-8.71), \mathrm{p}=0.014]$ and the need to come to the hospital to receive bDMARD [OR: 0.59 (Cl: 0.64-13.11), $\mathrm{p}=0.041$ ] caused unresponsiveness to return to the same bDMARD treatment and a significant increase in the risk of discontinuation of the biologic treatment. Conclusion: We conclude that it is important for patients to continue taking b/ tsDMARD treatments without interruption in the days past abnormal periods such as pandemic conditions and to make sufficient effort for minimum dose of CS and low disease activity by determining patient-based risk.

Table 1. Demographic and clinical characteristics of b/tsDMARDs patients

\begin{tabular}{|c|c|c|c|c|}
\hline & Total $(n=521)$ & $\begin{array}{c}\text { b/tsDMARD } \\
\text { Continue } \\
(n=424)(82.4 \%)\end{array}$ & $\begin{array}{c}\text { b/tsDMARD } \\
\text { Interruption }(+)(\mathrm{n}=97) \\
(17.6 \%)\end{array}$ & $\mathbf{P}$ \\
\hline & $\begin{array}{l}\text { Median (Min./ } \\
\quad \text { Max.) }\end{array}$ & $\begin{array}{l}\text { Median (Min./ } \\
\text { Max.) }\end{array}$ & Median (Min./Max.) & \\
\hline Age, years & $48(18 / 86)$ & $47(18 / 82)$ & $52(21 / 81)$ & $0.008^{t}$ \\
\hline Disease Duration, years & $11,2(2 / 43.3)$ & $130(22 / 490)$ & $142(22 / 519)$ & $0.41^{\mathrm{t}}$ \\
\hline \multirow[t]{2}{*}{$\begin{array}{l}\text { b/ts DMARD Duration, } \\
\text { months }\end{array}$} & $40(12 / 192)$ & $40(12 / 192)$ & $40(12 / 156)$ & $0.176^{t}$ \\
\hline & n (\%) & n (\%) & n (\%) & \\
\hline $\begin{array}{l}\text { Female } \\
\text { Most common rheumatic } \\
\text { diseases }\end{array}$ & $278(53.4)$ & $225(53.1)$ & $53(54.6)$ & 0.826 \\
\hline AxSpa or other SpA & $283(54.3)$ & $232(54.7)$ & $51(52.6)$ & 0.737 \\
\hline RA & $134(25.7)$ & $100(23.6)$ & $34(35.1)$ & $0.015^{\prime}$ \\
\hline PsA & $44(8.4)$ & $40(9.4)$ & $4(4.1)$ & 0.109 \\
\hline Vasculitis & $32(6.1)$ & $27(6.4)$ & $5(5.2)$ & 0.817 \\
\hline Others & $28(5.4)$ & $25(5.9)$ & $3(3.1)$ & 0.338 \\
\hline b/tsDMARD at Hospital/ & $140(26.9)$ & $102(24.1)$ & $38(39.2)$ & $0.004^{1}$ \\
\hline Health center & & & & $\begin{array}{l}\text { (OR: } \\
0.59)\end{array}$ \\
\hline $\begin{array}{l}\text { b/tsDMARD administra- } \\
\text { tion route (IV) }\end{array}$ & $137(26.3)$ & $100(23.6)$ & $37(38.1)$ & $0.005^{\prime}$ \\
\hline $\begin{array}{l}\text { Active/Progressive } \\
\text { Disease }\end{array}$ & $92(17.7)$ & $14(3.3)$ & $78(80.4)$ & $\begin{array}{r}<0.001^{1} \\
\text { (OR: } \\
4.8)\end{array}$ \\
\hline $\begin{array}{l}\text { Start/continue with the } \\
\text { same b/tsDMARD }\end{array}$ & 55 (10.6) & $3(0.7)$ & $52(53.6)$ & $<0.001^{p}$ \\
\hline $\begin{array}{l}\text { Unresponsiveness, b/ } \\
\text { tsDMARD switch }\end{array}$ & $16(3.1)$ & $9(2.1)$ & $7(7.2)$ & $0.017^{p}$ \\
\hline $\begin{array}{l}\text { b/tsDMARD stopped } \\
\text { permanently/deceased }\end{array}$ & $29(5.6)$ & $9(2.1)$ & $20(20.6)$ & $<0.001^{\mathrm{Hf}}$ \\
\hline $\begin{array}{l}\text { b/tsDMARD retention } \\
\text { (Total) }\end{array}$ & $474(91)$ & $406(95.8)$ & $68(70.1)$ & $<0.001$ \\
\hline
\end{tabular}

Independent Samples t Test (Bootstrap), ${ }^{\mathrm{P} P e a r s o n}$ Chi-Square Test (Monte Carlo), ${ }^{\text {If Fisher }}$ freeman Halton Test (Monte Carlo), 'Linear-by-Linear Association Test(Monte Carlo, Exact), SD.: Standard deviation; * OR, Odds Ratio,
Disclosure of Interests: None declared

DOI: 10.1136/annrheumdis-2021-eular.4068

\begin{tabular}{|l}
\hline AB0709 \\
CHARACTERIZATION OF NAILFOLD \\
CAPILLAROSCOPY IN COVID-19: A CASE CONTROL \\
STUDY
\end{tabular}

P. E. Bermudez Bermejo ${ }^{1}$, R. Jimenez-Soto ${ }^{2}$, A. Sanchez Rodríguez ${ }^{1}$, A. Turrent ${ }^{1}$, D. Mercado Velasco ${ }^{2}$, I. Bravo-Lee ${ }^{2}$, M. B. Colli-Cortés ${ }^{3}$, E. Alvarez Hernandez ${ }^{4}$, M. D. C. Amigo Castañeda ${ }^{1} .{ }^{1} A B C$ Medical Center, Rheumatology, Mexico City, Mexico; ${ }^{2}$ ABC Medical Center, Internal Medicine, Mexico City, Mexico; ${ }^{3}$ Regional Hospital "General Ignacio Zaragoza"ISSSTE, Rheumatology, Mexico City, Mexico; ${ }^{4}$ Hospital General de Mexico, Rheumatology, Mexico City, Mexico

Background: Nailfold capillaroscopy is a relatively easy-to-access, low-cost clinical tool that could help identify early coagulopathy in subjects with SARS-CoV-2, but specific findings vs. controls and its possible prognostic role has not been studied.

Objectives: To describe capillaroscopic findings and their usefulness in patients with COVID-19 compared to healthy controls.

Methods: We designed a cross-sectional study, carried out in a single care center for critical patients with SARS-CoV-2 pneumonia at the ABC Medical Center, Mexico City, which included patients from an intensive care unit (ICU) and internal medicine ward from March to April 2020. Demographic, biochemical and clinical features were collected. All patients signed the informed consent and the study was approved by the hospital ethics committee. All patients underwent nail capillary imaging of the 3 central fingers of each hand with a portable microscope with 60-100x magnification coupled to a smartphone with 7 megapixel images in an immersion medium. Capillaroscopy was performed in patients who did not have fever or hypothermia, or need vasopressors at the time of evaluation. Control subjects are healthy subjects matched on age and sex from a database of healthy controls without rheumatic diseases. Image evaluation of COVID-19 patients was performed in a blinded way for their characteristics. Prior to the analysis of the images, a pilot test was obtained with 4 rheumatologists in random cases, obtaining an acceptable global agreement in the visualization of capillaries and specific alterations of the nail bed. (Kappa $=0.58, p=0.0019$ ). Obtained data from capillaroscopies were used to be compared between severe and moderate cases of SARS-CoV-2 pneumonia. Additionally, we compared the findings against a healthy population in order to establish a reference.

Results: We included data from 27 patients and 32 controls with similar demographic features. Patients with COVID-19 patients had a mean age of $43+/-13.8$ years, $63 \%$ female. Comorbidities were present in $44.4 \%$ with: type II Diabetes Mellitus $18.5 \%$, systemic arterial hypertension $18.5 \%$, and rheumatoid arthritis $3.7 \%$. The mean length of stay time was $13+/-7.1$ days, $48.1 \%$ were admitted to the ICU, and $40.7 \%$ required invasive mechanical ventilation. In the capillaroscopic review remarkable findings of patients vs. controls were hemosiderin deposits ( 33 vs $12.5 \%, p=0.05$ ), less frequently observable capillaries ( 77 vs $100 \%, p=0.005$ ), any abnormality in capillaries (25.9 vs. $6.3 \%, p=0.03$ ). Of notice, specific findings in COVID-19 patients were capillary tortuosities in $19 \%$, dilatation in $9.5 \%$, serpentine pattern in $4.8 \%$, bush pattern in $9.5 \%$ and decreased density in only $4.8 \%$ of the cases. No avascular areas or capillaries of neoformation were observed. Finally, the presence of hemosiderin was associated with worse presentation and risk factors for severe COVID-19: Male sex 66.7 vs. $27.8 \%$, $(p=$ $0.024)$; Admission to ICU $77 \%$ vs $33 \%(p=0.029)$; $B M I>30 \mathrm{~kg} / \mathrm{m} 266.7$ vs. $27.8 \%(p=0.053)$. And risk for ICU admission OR $=7.0(95 \% \mathrm{Cl} 1.098$ 44.6). No significant associations were found for abnormalities in capillary morphology.

Conclusion: We present one of the first reports of nailfold capillaroscopic findings in patients with COVID-19 and the first to compare to healthy controls. Previous data on this regard suggests the presence of endothelial dysfunction and microvascular complications such as micro hemorrhage or micro thrombosis. Further studies may confirm these findings and prognostic value for worse outcomes in COVID-19 patients.

\section{REFERENCES:}

[1] Chen N, Zhou M, Dong X, et al. Epidemiological and clinical characteristics of 99 cases of 2019 novel coronavirus pneumonia in Wuhan, China: a descriptive study. Lancet. 2020;395:507-13.

[2] Cutolo M, Cortes S. capillaroscopic patterns in rheumatic diseases. Acta Reumatol Port. 2007 Jan-Mar;32(1):29-36. 